\title{
Quantitative Evaluation of the Effects of Acetazolamide in Friedreich's Ataxia: A Pilot Study
}

\author{
C.L. Richards, J.P. Bouchard, F. Dumas and D. Tardif
}

\begin{abstract}
We evaluated the effects of acetazolamide in 4 young patients with Friedreich's ataxia by clinical and quantitative laboratory methods. Dynamic muscle function of the lower extremity was measured during isokinetic knee movements and gait. The acetazolamide trial was terminated at 7 to 11 weeks because of reported side effects or increased ataxia in 3 of the patients. The quantitative evaluations revealed lower dynamic strength values and alterations in the gait movement pattern in all patients. These changes, which were interpreted as deterioration, were partially reversible with cessation of acetazolamide. The advantages of such quantitative evaluations of dynamic muscle function in the evaluation of therapy in Friedreich's ataxia are discussed.
\end{abstract}

RÉSUMÉ: Nous avons évalué cliniquement et en laboratoire de motricité les effets de l'acetazolamide chez 4 jeunes patients atteints d'ataxie de Friedreich. La fonction motrice dynamique du membre inférieur a été évaluée lors de mouvements isokinétiques et au cours de la marche. L'acetazolamide n'a été administrée que pour une période de 7 à 11 semaines étant donné que pour 3 patients cette médication a entrainé des effets secondaires ou une augmentation de l'ataxie. L'évaluation quantitative nous a permis de détecter que l'administration de l'acetazolamide était associée à une diminution de la force musculaire dynamique ainsi qu'à différentes perturbations motrices au cours de la marche. Ces changements se sont révélés partiellement réversibles après l'arrêt de la médication. Nous discutons aussi de l'importance des évaluations quantitatives de la fonction motrice lors d'essai thérapeutique dans l'ataxie de Friedreich.

Can. J. Neurol. Sci. $1984 ; 11: 554-560$

A pharmacological approach has been difficult to determine in Friedreich's ataxia (FA) most likely because of uncertainty as to the etiology and the conflicting mass of abnormal biological and biochemical findings in individual patients (for a review see Barbeau, 1982). Trials have implicated drugs acting on the metabolism of neurotransmitters or neuromodulators such as acetylcholine $(\mathrm{ACh})$, thyrotropin-releasing hormone (TRH) or gamma-amino-butyric acid (GABA). Thus reports that pyruvate oxidation abnormalities in FA (Barbeau et al., 1976; Blass et al., 1976) might result in a deficiency in brain ACh have led to the use of drugs acting on central cholinergic mechanisms. Although several studies have reported the use of physostigmine (Kark et al., 1977), oral choline (Legg, 1978; Barbeau, 1978) and lecithin (Barbeau, 1979), they have yielded conflicting results on the effects of these agents on motor functions in FA patients (Barbeau, 1978; Legg, 1978; 1979; Livingstone et al., 1981; Chamberlain et al., 1980; Pentland et al., 1981; Melancon et al., 1982).

Thyrotropin-releasing hormone, injected intravenously, has been reported to have short-lasting beneficial effects on motor functions in patients with spinocerebellar degeneration (Sobue et al., 1980; Yoshida et al., 1980). The mechanisms by which TRH acts are unclear but could be related to the normalisation of noradrenalin metabolism in the cerebellum and brainstem. Improvements in motor function following TRH injection have also been reported in a number of other experimental and clinical neurological conditions (Faden et al., 1982; Faden et al., 1982; Engel, 1983).

Legg (1979), reasoning that GABA is an important neurotransmitter of the cerebellum, tried baclofen, a GABA analogue, and sodium valproate, alone or in combination, in various hereditary or acquired cerebellar dysfunctions. When he observed significant deteriorations with this treatment he suggested the use of drugs which lowered rather than increased gabaergie activity. Similarly De Smet et al. (1982) did not find significant improvements in FA patients with gamma-vinyl GABA.

Recently, interest has focused on the role of carbonic anhydrase (CA) in the central nervous system (van Gelder, 1983). Acetazolamide, a potent CA inhibitor, has been reported to improve motor functions in patients with pyruvate dysmetabolism syn-

From the Centre de Recherche en Neurobiologie, Département des Sciences Neurologiques, Hôpital de I'Enfant-Jésus and Ecole de Réadaptation, Université Laval. Reprint requests for the complete supplement (Phase 3, Part 3) to: Prof. André Barbeau, Clinical Research Institute of Montreal, 10 Pine Avenue West, Montreal, Quebec, Canada H2W IR7 
dromes (Evans et al., 1978), familial periodic ataxia (Griggs et al., 1978), and both hyper and hypokalemic periodic paralysis (Resnick et al., 1968). It has also been used in the control of glaucoma and in the treatment of a number of other neurological conditions but not to our knowledge in FA.

We have recently (Bouchard et al., this issue) confirmed the beneficial effects reported by Griggs et al. (1978) with acetazolamide in patients with periodic ataxia. The later experience, in addition to pyruvate metabolism defects in FA (Barbeau et al., 1976; Blass et al., 1976) led us to investigate the effects of this drug in FA. We report the results of a pilot study on the effects of acetazolamide on some aspects of motor function in FA.

\section{SUBJECTS AND METHODS}

Since we were interested in the study of dynamic motor function of the lower extremity we selected four patients (age range: $11.17 \mathrm{yrs}$.) suffering from classical Friedreich's ataxia (Geoffroy et al., 1976) who could still walk unassisted. None of the patients had clinical or laboratory signs of hepatic, renal or cardiovascular insufficiency. The experimental nature of the study was explained to the adolescents and their parents prior to obtaining their informed consent. They were instructed about the side effects of the medication which include paresthesia, skin rash, marrow suppression and the formation of renal calculus.

Comparisons of the results of clinical, biochemical and quantitative evaluations of dynamic muscle strength and gait were used to determine the effects of acetazolamide therapy. These evaluations were made in a medication-free period before, during and after therapy. The duration of the acetazolamide therapy was limited to 7,9 or 11 weeks in individual patients because two of the patients reported unwanted side effects and an increase in gait ataxia. When the acetazolamide was stopped all the patients were given oral lecithin $(10 \mathrm{~g} /$ day $)$ and the evaluations were repeated 11 to 19 weeks later. In 2 patients this was a return to medication taken prior to initiation of this study.

Acetazolamide therapy was started with a dosage of $250 \mathrm{mg}$ taken in the morning. In the three male patients (cases 1, 2 and 4) the dosage was progressively increased by $250 \mathrm{mg}$ a week to a maximum dose of $250 \mathrm{mg}$ q.i.d. The dose was limited to $250 \mathrm{mg}$ t.i.d. in the female patient (youngest, case 3).

\section{Clinical and biochemical evaluations}

The functional stage of the disease was estimated with the ataxia clinical rating scale described by Pourcher and Barbeau (1980). Biochemical tests included: complete hemograms, venous Astrup, BUN, creatinine, $\mathrm{Na}, \mathrm{K}, \mathrm{Cl}$, protein electrophoresis, SGOT, SGPT and bilirubin, and urine analysis.

\section{Quantitative evaluations}

Dynamic strength (maximal voluntary) in the knee extensor and flexor muscles was measured with a strain gauge attached to a Cybex isokinetic dynamometer (Knutsson and Martensson, 1980). The FA patients were seated and restrained on a specially designed chair and surface electrodes were placed over six muscle groups (abductors, adductors, quadriceps, hamstrings, triceps surae and tibialis anterior) of the right lower extremity (Richards et al., 1980). Electrodes leads were connected to a Grass polygraph and the myosignals were amplified, rectified and time averaged (time constant $=0.02 \mathrm{~s}$ ). The electromyographic (EMG) activity in the quadriceps and hamstrings (respectively agonists and antagonists to the movements) was recorded concomitantly with the strength (torque) and knee angle data obtained with the isokinetic system on the polygraph as previously described (Richards et al., 1980). These data were then fed into a Digital LSI-11 computer for further recording and analysis, including corrections for torque resulting from gravitational force (Gransberg et al., 1980). In addition, the torque-angle curves produced by the knee extension and flexion movements (three repetitions for each movement) at $30 \% \mathrm{~s}$ and $120 \%$ were displayed on a storage oscilloscope for visual feedback.

After completion of the isokinetic movements, the electrodes were left in place and electronic footswitches were taped to the shoes to demarcate foot-floor contacts and define the gait cycle. Body and limb movements and muscle activations in the lower extremity were recorded with intermittent-light photography and electromyography during gait. The patients walked along a 8-metre walkway at their chosen (free) speed without assistance but accompanied for safety. Thus, a gait cycle was defined as the period between successive initial foot-floor contacts of the same lower extremity. The amplified EMG activity was recorded on the Grass polygraph for visual inspection (Knutsson and Richards, 1979) and subsequently rectified, time averaged and fed into the computer concomitantly with the footswitch signals for the recording and analysis of about 20 gait cycles (Isaksson and Knutsson, 1980; Knutsson, 1981).

Patterns of gait movements were recorded with an intermittentlight photography system developed in our laboratory. Rows of light-emiting-diodes (LEDs) were fixed to the lateral aspect of the neck, upper arm, lower arm, thigh, lower leg and foot and shoulder and pelvic harnesses which contained LEDs visible from above were attached to the patients. With the LEDs flashing in synchrony at $2 \mathrm{OHz}$ and in semi-darkness (reduced lighting), the patients walked across the fields of view of two $35 \mathrm{~mm}$ cameras placed to the side (for records of the sagittal plane movements) and overhead (for recording of the transverse trunk and pelvic rotations and lateral displacements). The positions of the LEDs in time during the walking cycle was thus recorded with lights indicating footfloor contacts (footswitches).

Negatives of the side and overhead views were projected onto an $x-y$ magnetic tablet and the successive positions of the LEDs during the gait cycle were digitized and temporal components, linear and angular displacements analyzed by computer (Normand et al., 1984). Several gait cycles in the patients (usually 5) were measured to derive mean values which were compared to normal data obtained in 10 normal men (27.4 \pm 4.0 yrs., mean \pm ISD) with the same procedure because comparative data was unavailable in normal teen-age subjects. Although differences related to age and sex have been described in adult gait (Murray et al., 1964; Murray et al., 1970), the fundamental gait movement pattern is very reproducible (Knutsson and Richards, 1979) and the adult pattern is apparently developed in children by the age of seven (Sutherland et al., 1980).

\section{Results}

\section{Clinical findings}

When case 1 (male, age 17) attained the full dosage of acetazolamide he began to lose his appetite, have a reduced activity level and be somnolent. He lost $4.1 \mathrm{~kg}$ and his gait was 
judged more ataxic by all observers. Acetazolamide therapy was stopped at 7 weeks at which time a mild, hyperchloremic metabolic acidosis was found. After therapy, with the addition of lecithin he recovered his appetite and former activity levels after a few days, and gradually regained his weight loss. The gait performance, however, did not return to the pre-study level.

A reduced activity level, somnolence, and increased gait ataxia (without weight loss) was observed by the parents in case 2 (male, age 14). On neurological examination the only obvious changes were increased saccadic pursuit eye movements and the appearance of occasional action myoclonus. Therapy was stopped after 9 weeks but re-instated for 36 hours prior to electrophysiological and photographic evaluations at 11 weeks, after which acetazolamide was discontinued and lecithin was prescribed for the first time.

In case 3 (female, age 11), sister of case 2, the total dosage of acetazolamide was limited to $750 \mathrm{mg}$ per day because of her small size $(26.9 \mathrm{~kg})$. She did not present somnolence or increased gait ataxia but lost $2.3 \mathrm{~kg}$ during the 11 week treatment period. When acetazolamide therapy was stopped she was put on lecithin and regained her weight loss within 2 months.

Case 4 (male, age 15) did not report any side effects or subjective increase in gait ataxia during the 11 week therapy period. Acetazolamide was nevertheless withdrawn and lecithin therapy was re-instituted.

In summary, the parents of two of the patients (cases 1 and 2) reported somnolence, reduced activity levels and an increase in gait ataxia which was accompanied by weight loss in case 1 . In a third patient (case 3) weight loss was not associated with changes in her clinical status. Only one patient (case 4) was apparently free from side effects and was both subjectively and clinically stable while on acetazolamide therapy. We found that the ataxia clinical rating scale was not sensitive enough to allow the neurologist to quantify the subtle changes which occurred in the motor functions of the patients during the study.

\section{Biochemical tests}

The pre-study biochemical analyses indicated a discrete acidosis of the venous blood ( $\mathrm{pH}$ about 7.3) with normal electrolytes, BUN, creatinemia, SGOT, SGPT and hemograms in the four patients. After 7 and 9 weeks on acetazolamide, cases 1 and 2 had even more reduced venous $\mathrm{pH}$ values of 7.21 and 7.23 respectively. All the patients had reduced serum bicarbonate and a higher chloride concentration (range: $111-117 \mathrm{mEq} / 1$ ) with acetazolamide. Urine density and $\mathrm{pH}$ did not change $\mathrm{pH}$ 6.0 ) in any of the patients. Although case 1 had a history of hyperbilirubinemia, his pre-study bilirubin value was within normal limits $(0.8 \mathrm{mg} \%)$ and did not change with acetazolamide.

\section{Dynamic strength}

Figure 1 illustrates the mean changes $(n=4)$ in the moment of muscle force (torque) produced at the 45 degree knee angular position during the isokinetic movements in the three treatment conditions: before acetazolamide (open bars), after 7 to 11 weeks of acetazolamide (stippled bars) and 11 to 19 weeks after cessation of acetazolamide and institution of lecithin therapy (striped bars). Measurements of the torque at this angular position were chosen to avoid the deflection produced by the impact torque when the predetermined angular velocity is reached (Richards, 1981).
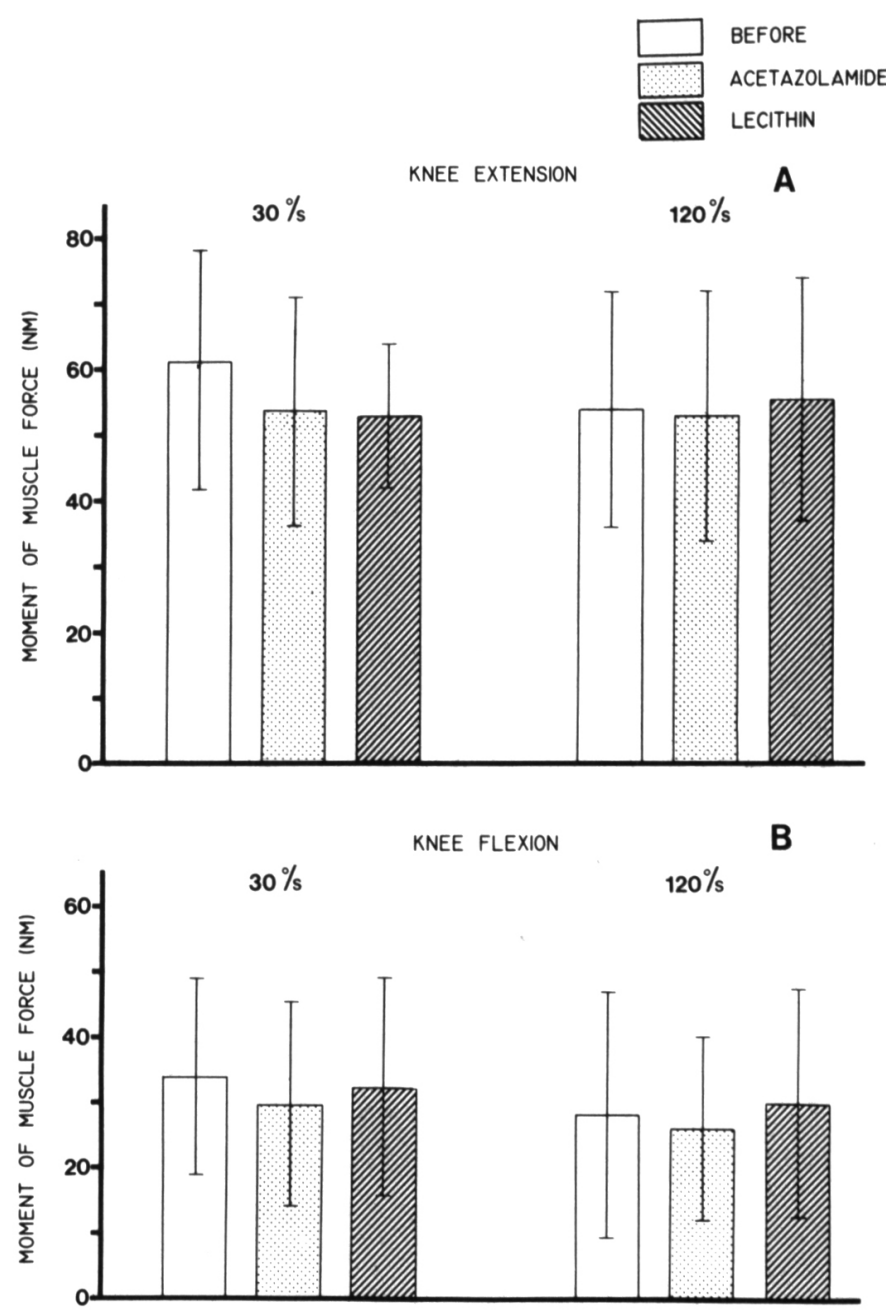

Figure I - The mean moment of muscle force $(\mathrm{Nm})$ developed at the $45^{\circ} \mathrm{knee}$ angular position during isokinetic knee extension $(A)$ and flexion $(B)$ movements at $30 \%$ and $120^{\circ} / \mathrm{s}$. Values given in mean $\pm I S D(n=4)$ before (open bars), with acetazolamide (stippled bars) and with lecithin (striped bars) therapy.

The mean torque produced is similar for the three treatment conditions for both extension and flexion movements at $30 \%$ and $120 \%$. Despite the similarities, a trend toward reduced torque values occurs with acetazolamide therapy, particularly during the movements at $30 \%$. There is also a trend toward increased torque after cessation of acetazolamide and institution of lecithin therapy except for extension $30 \%$ movements. The small number of patients restricted the use of statistical tests to verify the group changes. All the patients, did, however, have lower torque values with acetazolamide during the movements at $30 \%$ s. For knee extension the reductions ranged from 9 to $17 \%$ and for knee flexion 4 to $36 \%$. After therapy, with lecithin, these values (as compared to acetazolamide) increased 9 and $25 \%$ in cases 2 and 3 and decreased 5 and $18 \%$ in cases 1 and 4 for extension movements. In the flexion movements the torque was increased 4,4 and $15 \%$ in cases 1,2 and 4 and decreased $5 \%$ in case 3 , respectively.

These changes in torque values during the study could not be attributed to changes in the antagonist muscle coactivation levels (Richards et al., 1980). With acetazolamide, however, 


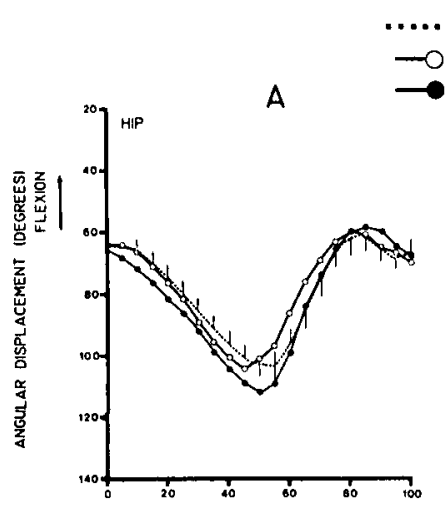

-... normal subjects

ACETAZOLAMIDE

D
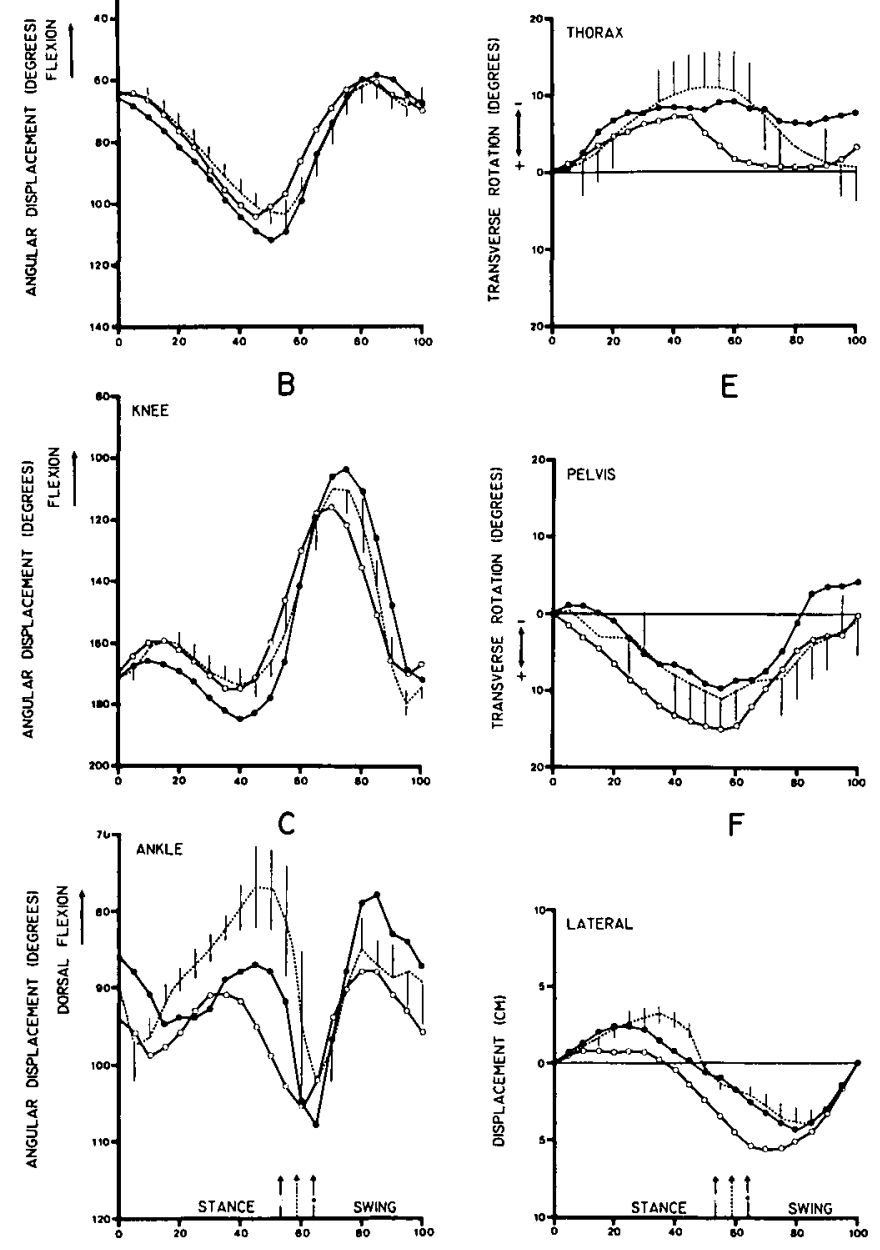

GAIT CYCLE (\%)

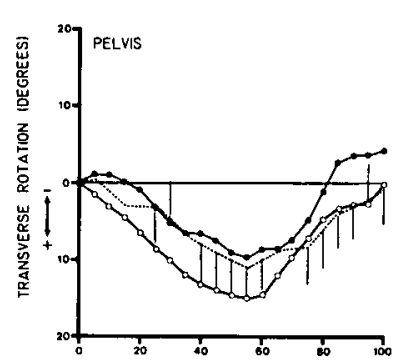

F

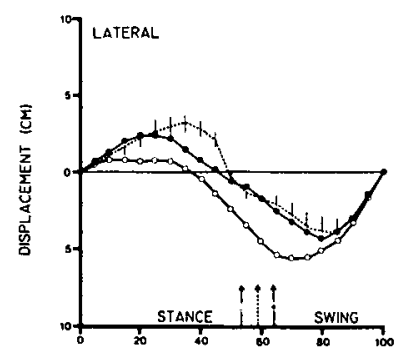

GAIT CYCLE (\%)

Figure 2 - Gait movement patterns in a 15 years old male FA patient (case 4) before (open circles) and with acetazolamide (full circles) therapy in comparison to normal men (dotted lines, mean $\pm 1 S D, n=10$ ). Angular movements and displacements given on y-axis and percent of gait cycle on $x$-axis. Curves of movements measured from intermittent-light photographs in side ( $A-C)$ and overhead (D-F) views begin and end at successive foot-floor contacts of the same foot. Data represent mean of 5 (before) and 4 (during) gait cycles in patient for sagittal movements $(A-C)$ and 3 cycles for transverse rotations ( $D$ and $E$ ) and lateral movements $(F)$.

the peak EMG activity level in the agonists was higher (both extension and flexion movements at $30 \%$ s) in all the patients relative to before values. In three cases $(2,3$ and 4$)$, this increase in extension movements was due to a high initial burst of activity in the quadriceps at the beginning of the movement, which was, however, not sustained throughout the movements. After, with lecithin, the peak EMG activity levels in the agonists tended to be intermediate between before and acetazolamide values.

\section{Gait analysis}

To illustrate the abnormal gait movement patterns and the types of changes which occurred with acetazolamide therapy,

the curves of movements measured from the recordings of the gait movements in one patient (case 4) are shown in Figure 2. It gives the angular displacements (y-axis) of the hip, knee and ankle joints (A-C), transverse rotations of the trunk and pelvis (D-E) and lateral (F) displacements during the gait cycle (in percent on the $\mathrm{x}$-axis) before (open circles) and after 11 weeks of acetazolamide therapy (full circles) in comparison to curves of normal values.

As can be seen in the displacement curve of the patient before therapy, the hip (A) was relatively flexed at the beginning of the cycle, extended during the first $45 \%$ of the cycle, then reversed into flexion. The curve during the swing phase had a deflection into extension at $80 \%$ of the cycle. Differences as compared to the normal curve can be seen in the patient's increased flexion in early and mid-swing phase. Deviations in the knee movement (B) are seen in the reduced flexion in mid-swing phase. In the ankle (C), the dorsiflexion was decreased in mid-stance, the plantar flexion increased and early in late stance and the dorsiflexion decreased in late swing phase. With acetazolamide, the hip displacement curve is more extended throughout most of the stance phase and more flexed in late swing. The knee movement curve with acetazolamide shows increased stance phase extension reaching into hyperextension, and increased flexion in swing. At the ankle, there is more dorsiflexion in early and mid-stance and in late swing.

Before acetazolamide, deviations from normal values in the thorax rotations (D) occur in early swing and in the pelvis throughout much of the stance phase. With acetazolamide the thorax and pelvis rotation curves are similar to the normal curves except in late swing where, in both, an excessive counterclockwise movement can be seen. The lateral displacement curve (with acetazolamide) appears more similar to the normal curve. In this patient the cycle duration, increased from $1.09 \pm$ $0.10 \mathrm{~s}$ to $1.19 \pm 0.06 \mathrm{~s}$; the stride length from $143.4 \pm 6.7 \mathrm{~cm}$ to $145.3 \pm 9.7 \mathrm{~cm}$ and the velocity decreased from $132.3 \pm 12.2 \mathrm{~cm} / \mathrm{s}$ to $122.4 \pm 7.9 \mathrm{~cm} / \mathrm{s}$ with acetazolamide.

Individual changes in the other patients with therapy, although different in many respects, did display characteristics similar to those shown in Fig. 2. The displacement curve of the hip showed an increase in stance phase extension in three of the patients (cases 1, 3 and 4), and an increase in late swing flexion in cases 1, 3 and 4. At the knee, three (cases 1,2 and 4) had greater extension in stance which resulted in hyperextension in two (cases 2 and 4), and increased late swing phase knee flexion was observed in three patients (cases 1, 3 and 4). The most obvious changes at the ankle with therapy were increase dorsiflexion in early stance and late swing phase in all the patients. Three (cases 2, 3 and 4) had increased counterclockwise movements of the pelvis and thorax in late swing and a lateral displacement curve more similar to normal with acetazolamide (comparisons were not possible in case 1).

Changes in the gait displacement curves were also observed in the individual patients when evaluated while on lecithin therapy ( 11 to 19 weeks) following cessation of the acetazolamide. The angular displacements tended to return to the before study values. This was particularly noticeable in the sagittal movements but could also be seen in the transverse rotations and lateral displacements.

The EMG analysis of the muscle activations in the lower extremity during gait in the different patients revealed differences in the muscle activation patterns when compared to 
normal patterns (Knutsson and Richards, 1979; Knutsson, 1981). For example, in the before analyses, a prolonged stance phase activation of the quadriceps was seen in the 3 older patients while in cases 2 and 3 there was an extra mid-stance phase activity peak in the hamstrings. An early or secondary peak of activation of the triceps surae occurred in cases 1,2 and 3 and the tibialis anterior exhibited excessive early and mid-swing phase activity in all the patients. With acetazolamide the profiles (timing) of the EMG activity curves remained similar to the before acetazolamide curves in most of the muscles, although some changes occurred in the stance phase pattern of activation in the hamstrings and triceps surae in case 2 and 3. The amplitude level of the EMG activity curves were, however, usually higher in all the muscles but particularly in the quadriceps with increases greater than 104\% (peak EMG amplitude comparisons) in 3 cases. After therapy, with lecithin the EMG activity profiles remained, in general, similar to those obtained with acetazolamide while both increased and decreased amplitude levels were found in different muscles in individual patients.

\section{Discussion}

In this study we evaluated the effects of acetazolamide therapy in four young patients with FA. Effects of therapy were determined by clinical assessments and quantitative evaluations of lower extremity motor function. The performance of the patients was measured during isokinetic knee movements under strong volitional drive and gait a semi-automatic movement requiring a minimum of volitional drive and largely dependent on preprogrammed central commands (Grillner, 1975). Muscle activations in participating muscles were recorded during both movements.

Before therapy, deviations from normal movement and muscle activation patterns were observed during gait in all the patients. These deviations were accentuated with acetazolamide therapy. For instance, the flexion movements in the swing phase and knee extension in the stance phase were exaggerated and timing abnormalities in the sequence of the knee movements during gait altered with acetazolamide therapy. These gait movement deviations are likely related to disorders in the amplitude, direction, rate, regularity and force of the limb movements as well as to delays in stops and starts (Holmes, 1939; Brooks and Thach, 1981) and disturbed mechanisms of postural control (Nashner and Grimm, 1978; Grimm, 1983) described in patients with cerebellar dysfunctions. Since the term ataxia is used to encompass such movement disorders, the gait movement deviations in the FA patients can be interpreted as manifestations of gait ataxia.

In the FA patients studied, the mechanism of knee hyperextension in the stance phase with acetazolamide appears to be related to the prolonged and high EMG activity in the quadriceps in combination with the ataxic movements. Knee hyperextension, is a common movement disorder in patients with motor dysfunctions of various origins. It is recognized as a functional compensation to provide stability in patients with muscle weakness of peripheral origin (Perry, 1974) and in hemiplegic patients who lack adequate muscle activations to control the knee and ankle movements in stance (Richards and Knutsson, 1974; Bogardh and Richards, 1979). Early stance phase activity in the triceps surae in patients with spasticity (Richards and Knutsson 1974; Simon et al., 1978) and excessive coactivation of several limb muscles (Bogardh and Richards 1974; Knutsson and Richards, 1979) can also lead to knee hyperextension. The large increase in the amplitude level of the quadriceps EMG activity which was accompanied by smaller amplitude level increases in the other muscles with acetazolamide suggest a greater effort to walk and a more inefficient movement pattern (Richards, 1980).

Changes in dynamic strength with acetazolamide were not large but the values were consistently lower in the $30 \%$ movements. Increased coactivation of antagonist muscles could not explain the strength decreases because the coactivation levels were similar before and during acetazolamide therapy (Richards, 1980; Gransberg et al., 1980). Since we observed a slight increase in the peak EMG agonist activity, the reduced strength did not appear to be due to a diminished capacity to recruit motor units but rather to a reduced capacity to maintain high levels of EMG activity throughout the movements since greater fluctuations were observed in the agonist activation curve. These were correlated to oscillations in the torque-angle curves. We have previously reported such oscillations in more severely affected FA patients (Richards et al., 1980). These changes in the isokinetic movement and EMG parameters can also be interpreted as manifestations of increased motor control dysfunctions (for a review see Brooks and Thach, 1981) which cannot be expressed as changes in the rate or limb movement abnormalities because the leg is fixed to the apparatus and the maximal angular velocity of the movements in one plane is pre-determined.

The quantitative tests thus revealed a loss of strength in the $30 \%$ movements and alterations in the gait movement pattern in all the patients with acetazolamide therapy. It is not likely that the signs of increased dysfunction can be attributed to non specific effects of the therapy since one patient (case 4) did not report any side effects and the only biochemical change was a mild elevation in the chloride ion concentration. Nevertheless, during therapy he had both a torque reduction of $12 \%$ for extension $30 \% \mathrm{~s}$ movements and changes in his gait are illustrated in Fig. 2.

The duration of acetazolamide therapy in these patients was limited to 7 to 11 weeks because three of the patients reported troublesome side effects including for two of these reduced activity levels, somnolence, weight loss and increased gait ataxia. These effects were alarming to the parents who interpreted them as signs of deterioration. When the acetazolamide was stopped, the parents (in 2 cases) requested a return to lecithin, the pre-study medication. Since we have measured improvements in dynamic strength in young FA patients (unpublished results) and that similar effects were reported by Melançon et al. (1982) in younger patients in functional stage one with lecithin, all the patients were put on lecithin therapy. Evaluations of muscle strength and gait made after a period of lecithin showed that the changes observed with acetazolamide therapy were at least partially reversible. The improvements in clinical status, dynamic strength and gait cannot, however, be solely attributed to the institution of lecithin, and it is likely that removal of acetazolamide contributed to the changes.

In light of the present study it can be seen that objective evaluations make it possible to detect modifications in dynamic function that otherwise would not be seen. For instance, in the gait analysis, very precise parameters pertaining to the ampiitude and timing of the gait movements, the interplay among different 
components, as well as muscle activations are measured. From these measurements it is possible to quantify the changes and also to describe pattern variations. These data in turn, can be used to study the effects of therapy and provide insight into mechanisms of motor control which can lead to a better understanding of the dysfunction.

Although isokinetic movements (Richards et al., 1980) and gait analysis have not been applied to the evaluation of therapy in FA, these methods have been tested and used in the evaluation of therapies in patients with other movement disorders of neurological origin (Richards and Knutsson, 1974; Bogardh and Richards, 1974; Knutsson and Martensson, 1976; Barbeau et al., 1982; Richards et al., 1983; Knutsson, 1983). In FA patients the combination of isokinetic and gait evaluations gives information on the relative importance of different components which contribute to the motor dysfunction during volitional and semi-automatic movements.

In conclusion, we were unable to demonstrate beneficial effects with 7 to 11 weeks of acetazolamide therapy in 4 young patients with FA. On the contrary, the effects of therapy were interpreted as deterioration and led to the termination of the trial. Acetazolamide appeared to act on mechanisms involved in the control of the movement dysfunction and these effects were at least partially reversible. The results of the present study emphasize the need for quantitative analyses of changes in motor function in therapeutic evaluations.

\section{ACKNOWLEDGEMENTS}

This work was supported by grants from the Association Canadienne de l'Ataxie de Friedreich and l'Institut de Recherche en Santé et Sécurité du Travail (IRSST). We thank M. Baron for typing the manuscript.

\section{REFERENCES}

Barbeau A (1978) Emerging treatments. Replacement therapy with choline or lecithin in neurological disease. Can J Neurol Sci 5: 157-160.

Barbeau A (1979) Lecithin in movement disorders. In: Nutrition and the Brain. Vol 5, Barbeau A, Growdon HH, Wurtman RJ (eds) New York, Raven Press, pp 263-271.

Barbeau A (1982) Friedreich's disease 1982: Etiologic hypotheses. A personal analysis. Can J Neurol Sci 9: 243-263.

Barbeau A, Butterworth RF, Ngo T, Breton G, Melançon S, Shapcott D, Geoffroy G, Lemieux B (1976) Pyruvate metabolism in Friedreich's ataxia. Can J Neurol Sci 3: 379-388.

Barbeau H, Richards CL, Bédard PJ (1982) Action of cyproheptadine in spastic paraparetic patients. J Neurol Neurosurg Psychiatry, 45: 923-926.

Blass JP, Kark RAP, Menon NK, Harris SE (1976) Low activities of pyruvate and oxoglutarate dehydrogenase complex in five patients with Friedreich's ataxia. N Engl J Med 295: 62-67.

Bogardh E, Richards CL (1974) Gait analysis and re-learning of gait control in hemiplegic patients. In: Seventh International Congress, World Confederation for Physical Therapy, Montreal, pp 443-453.

Bouchard JP, Roberge C, van Gelder NM, Barbeau A (1984) Familial periodic ataxia responsive to acetazolamide. Can J Neurol Sci (this issue).

Brooks VB, Thach WT (1981) Cerebellar control of posture and movement. In: Handbook of Physiology - The Nervous System II, vol 2, Part 2, Brooks VB (ed). American Physiological Society, Bethesda, Maryland, pp 877-946.

Chamberlain S, Robinson N, Walker J, Smith C, Benton S, Kennard C, Swash M, Kilkenny B, Brandbury S (1980) Effect of lecithin on disability and plasma free-choline levels in Friedreichs ataxia. J Neurol Neurosurg Psychiatry 43: 843-845.
De Smet Y, Mear JY, Tell G, Schechter PJ, Lhermitte F, Agid Y (1982) Effect of gamma-viny! GABA in Friedreich's ataxia. Can J Neurol Sci 9: 171-174.

Engel WK, Siddique T, Nicoloff JT (1983) TRH acutely in amyotrophic lateral sclerosis (ALS) patients causes increased mobility and strength, lessened spasticity, shivering, and tachypnea. Neurology, 33 (suppl 2): 120-121, abstract.

Evans OB, Kilroy AW, Fenichel GM (1978) Acetazolamide in the treatment of pyruvate dysmetabolism syndromes. Arch Neurol 35: 302-305.

Faden AI, Jacobs TB, Holaday JW (198I) Thyrotropin-releasing hormone improves neurologic recovery after spinal trauma in cats. $\mathrm{N}$ Engl J Med 305: 1063-1067.

Faden AI, Hallenbeck JM, Brown CQ (1982) Nalaxone vs thyrotropinreleasing hormone in the treatment of experimental stroke. Neurology 32: 1083-1087.

Geoffroy G, Barbeau A, Breton G, Lemieux B, Aubé M, Léger C, Bouchard JP (1976) Clinical description and roentgenologic evaluation of patients with Friedreich's ataxia. Can J Neurol Sci 3: 279-286.

Gransberg L, Knutsson E, Litton JE (1980) A computer programmed system for the analysis of active and passive isokinetic movements. In: IEEE Frontiers of Engineering in Health Care, Washington, pp 292-295.

Griggs RC, Moxley RT, Lafrance RA, McQuillen J (1978) Hereditary paroxysmal ataxia: response to acetazolamide. Neurology 28 : 1259-1264.

Grillner S (1975) Locomotion in vertebrates: central mechanisms and reflex interaction. Physiol Rev 55: 247-304.

Grimm RJ (1983) Program disorders of movement. In: Advances in Neurology, Vol 39, Motor Control Mechanisms in Health and Disease, Desmedt JE (ed). New York, Raven Press, pp 1-12.

Holmes G (1939) The cerebellum of man. (The Hughlings Jackson memorial lecture). Brain 62: 1-30.

Isaksson AI, Knutsson E (1980) Microcomputer implementation of gait examination in clinical routine. I $n$ : IEEE Frontier's of Engineering and Health Care, Washington, pp 42-45.

Kark RAP, Blass JP, Spence MA (1977) Physostigmine in familial ataxias. Neurology 27: 70-72.

Knutsson E (1981) Gait control in hemiparesis. Scand J Rehab Med 13: 101-108.

Knutsson E (1983) Analysis of gait and isokinetic movements for evaluation of antispastic drugs or physical therapies. In: Advances in Neurology, Vol, 39, Motor Control Mechanisms in Health and Disease, Desmedt JE (ed) New York, Raven Press, pp 1013-1034.

Knutsson E, Martensson A (1976) Action of dantrolene sodium in spasticity with a low dependence of fusimotor drive. J Neurol Sci 29: 195-212.

Knutsson E, Martensson A (1980) Dynamic motor capacity in spastic paresis and its relation to prime mover dysfunction, spastic reflexes and antagonist co-activation. Scand J Rehab Med 12: 93-106.

Knutsson E, Richards CL (1979) Different types of disturbed motor control in gait of hemiparetic patients. Brain 102: 405-430.

Legg NJ (1978) Oral choline in cerebellar ataxia. Brit Med J ii: 1403.

Legg NJ (1979) Oral choline in cerebellar ataxia. Brit Med J ii: 133.

Livingstone IR, Mastaglia FL, Pennington RJT, Skilbeck C (1981) Choline chloride in the treatment of cerebellar and spinocerebellar ataxia. J Neurol Sci 50: 161-174.

Melançon JB, Vanasse M, Geoffroy G, Barabé L, Proulx A, Fontaine G, Dallaire L, Potier M (1982) Oral lecithin and linoleic acid in Friedreich's ataxia. II. Clinical results. Can J Neurol Sci 9: 155-164.

Murray MP, Drought AB, Kory RC (1964) Walking patterns of normal men. J Bone Joint Surg 46-A: 335-360.

Murray MP, Kory RC, Sepic S (1970) Walking patterns of normal women. Arch Phys Med Rehabil 51: 637-650.

Nashner LM, Grimm RJ (1978) Analysis of multiloup dyscontrols in standing cerebellar patients. In: Progress in Clinical Neurophysiology, Vol. 4. Cerebral Control in Man: Long Loop Mechanisms, Desmedt JE (ed) Karger, Basel, pp 300-319.

Normand MC, Richards CL, Filion M, Dumas F, Tardif D (1984) A simplified method for tridemensional analysis of gait movements. In: Biomechanics IX-A, Winter D, Wells R, Norman R, Hayes K and Patla A (eds). Human Kinetics Publishers, Champaign, Illinois (in press). 
Pentland B, Martyn CN, Steer CR, Christie JE (1981) Lecithin in Friedreich's ataxia. Br Med J, 282: 1197-1198.

Perry J (1974) Kinesiology of lower extremity bracing. Clin Orthop Rel Res 102: 18-31.

Pourcher E, Barbeau A (1980) Field testing of an ataxia scoring and staging system. Can J Neurol Sci 7: 339-344.

Resnick JS, Engel WK, Griggs RC, Stam AC (1968) Acetazolamide prophylaxis in hypokalemic periodic paralysis. N Engl J Med 278: 582-586.

Richards CL (1980) Dynamic Muscle Function in Human Normal, Pathological and Prosthetic Knee Joints. PhD Thesis. McGill University, Montreal, 1980.

Richards CL (1981) Dynamic strength characteristics during isokinetic knee movements in healthy women. Physiother Can 33: 2-11.

Richards CL, Bédard PJ, Fortin G, Malouin F (1983) Quantitative evaluation of the effects of L-dopa in torsion dystonia: A case report. Neurology, 33: 1083-1087.

Richards CL, Bouchard JP, Bouchard R, Barbeau H (1980) A preliminary study of dynamic muscle function in hereditary ataxia. Can $\mathbf{J}$ Neurol Sci 7: 367-377.
Richards CL, Knutsson E (1974) Evaluation of abnormal gait patterns by intermittent-light photography and electromyography. Scand J Rehab Med Suppl 3: 61-68.

Simon SR, Deutsch SD, Nuzzo RM, Mansour MJ, Jackson JL, Koskinen M, Rosenthal RK (1978) Genu recurvatum in spastic cerebral palsy J Bone Joint Surg 60-A: 822-894.

Sobue I, Muroga T, Konagaya M, Yamamoto H, Mitsuma T, Takayanagi $T$ (1980) Effects of thyrotropin-releasing hormone on ataxia in spinocerebellar degenerations. In: Spinocerebellar Degenerations. I Sobue (ed). University Park Press, Baltimore, pp 83-92.

Sutherland DH, Olshen R, Cooper L, Woo Sly (1980) The development of mature gait. J Bone Joint Surg 62A: 336-353.

van Gelder NM (1983) Metabolic interactions between neurons and astroglia: glutamine synthetase, carbonic anhydrase and water balance. In: Basic Mechanisms of Neuronal Excitability. Jasper $\mathrm{HH}$ and van Gelder NM, (eds) Alan R Liss, New York, pp 5-29.

Yoshida M, Shimizu N, Niijima K, Mizuno M (1980) Pathophysiology of ataxia and ocular disturbance in SCD with quantitative evaluation of TRH treatment. In: Spinocerebellar Degenerations. I Sobue (ed). University Park Press, Baltimore, pp 251-256. 